DOI: 10.31660/0445-0108-2019-3-47-53

УДК 622.279.23

\author{
Влияние нестационарного режима работы \\ на продуктивность добывающих скважин \\ Уренгойского нефтегазоконденсатного месторождения
}

\author{
В. В. Инякин ${ }^{1}$, С. Ф. Мулявин ${ }^{1}$, И. А. Усачев ${ }^{2}$ \\ ${ }^{1}$ Тюменский индустриальный университет, г. Тюмень, Россия \\ ${ }^{2}$ НАО «Сибирский научно-аналитический иеетр», г. Тюмень, Россия \\ *e-mail:injakinvv@tyuiu.ru
}

Аннотация. Разработка нефтегазоконденсатных месторождений сопровождается фазовыми превращениями пластовых углеводородных смесей, то есть переходом конденсата из газового состояния при пластовом давлении ниже давления начала конденсации. Ретроградная конденсация приводит к снижению фазовой проницаемости в призабойной зоне, что влечет за собой снижение уровней добычи газа и газового конденсата. В работе рассматриваются данная проблематика и возможные направления ее решения методом нестационарной работы скважин, на которых проведен гидроразрыв пласта. Представленная проблема актуальна в условиях низкопроницаемых коллекторов с аномально высоким пластовым давлением и значительным потенциальным содержанием конденсата.

Ключевые слова: газоконденсатная система; увеличение продуктивности; потенциальное содержание конденсата; дебит газоконденсатной смеси

\title{
Unsteady-state conditions of producing wells at of the Urengoy oil and gas condensate field influences their efficiency
}

\author{
Vladislav V. Inyakin ${ }^{1}$, Semen F. Mulyavin ${ }^{1}$, Igor A. Usachev ${ }^{2}$ \\ ${ }^{1}$ Industrial University of Tyumen, Tyumen, Russia \\ ${ }^{2}$ Siberian scientific-analytical centre NJSC, Tyumen, Russia \\ *e-mail:injakinvv@tyuiu.ru
}

Abstract. The development of oil and gas condensate fields is accompanied by phase transformations of reservoir mixtures, i.e. the when the bottomhole pressure drops below the dew point pressure, the liquid condensate becomes versatile and enters the gas phase. Retrograde condensate leads to a decrease in phase permeability in the bottomhole. As a result, it also leads to a decrease in production levels is reduced both by gas and natural gas liquids. The article considers this challenge and its possible solutions by the method of unsteady-state conditions well efficiency, on which the hydraulic fracturing was carried out. The issue of well efficiency is urgent in conditions abnormally high reservoir pressure and considerable condensate yield.

Key words: gas-condensate system; production gain; condensate yield; gascondensate mixture production rate 


\section{Введение}

Снижение продуктивности скважин в процессе разработки газоконденсатных месторождений связано с проявлением различных геолого-промысловых факторов. Основными из них являются следующие:

- $\quad$ осложнение в эксплуатации скважины из-за ухудшения технического состояния ствола скважины;

- изменение состояния призабойной зоны скважины (ПЗС) за счет ухудшения фильтрационно-емкостных свойств коллектора;

- накопление жидкости в стволе скважины вследствие изменения фазового состояния углеводородной смеси или прорыва воды [1].

В настоящее время имеется значительное количество научных работ [1-15] в области воздействия на призабойную зону пласта (ПЗП) газоконденсатных скважин с целью увеличения их продуктивности, либо ее поддержания на определенном уровне. В столь сложных геолого-географических и термобарических условиях наибольшее распространение получила технология гидравлического разрыва пласта (ГРП) в наклонно направленных и горизонтальных скважинах. Использование иных методов, таких как тепловая обработка, изменение смачиваемости коллектора, кислотная обработка, акустическое воздействие, обработка углеводородными и неуглеводородными агентами, не получило широкого распространения за счет ограниченности применения, значительных затрат и быстрого исчезновения эффекта.

Описание различных моделей течения газоконденсатных смесей приводится в работах [16-19]. Рассмотрим типовую модель фильтрации (рис. 1), чтобы детально представить динамические фазовые процессы в пластовой системе (описание производится справа налево).

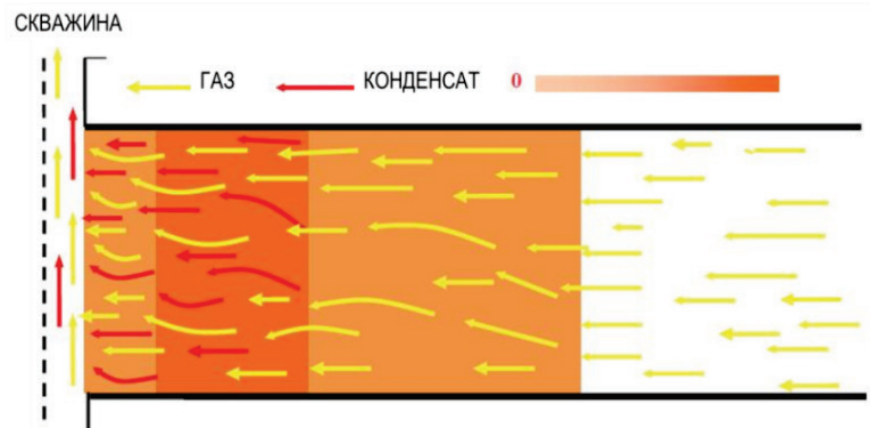

Рис. 1. Типовая модель распределения конденсата с учетом движения флюида в пласте

В зоне № 1 происходит однофазная фильтрация, так как пластовое давление в этой зоне выше давления начала конденсации. В зоне № 2 также происходит однофазная фильтрация, однако давление в этой зоне ниже давления начала конденсации, и выпавший конденсат находится в капельном виде. В зоне № 3 происходит двухфазная фильтрация газа и конденсата. Это обусловлено тем, что конденсат в этой зоне находится в пленочном состоянии и не удерживается за счет капиллярных сил. Зона № 4 обычно расположена в ПЗП, здесь, так же как и в зоне № 3, происходит двухфазная фильтрация, однако насыщенность ретроградным конденсатом ниже за счет высокоскоростного движения пластового флюида. 


\section{Объект и предмет исследования}

Уренгойское месторождение входит в число крупнейших газовых и газоконденсатных месторождений мира, а также занимает первое место в Западной Сибири по запасам. Геологический разрез месторождения представлен залежами сеномана, неокома, ачимовскими и юры (рис. 2).

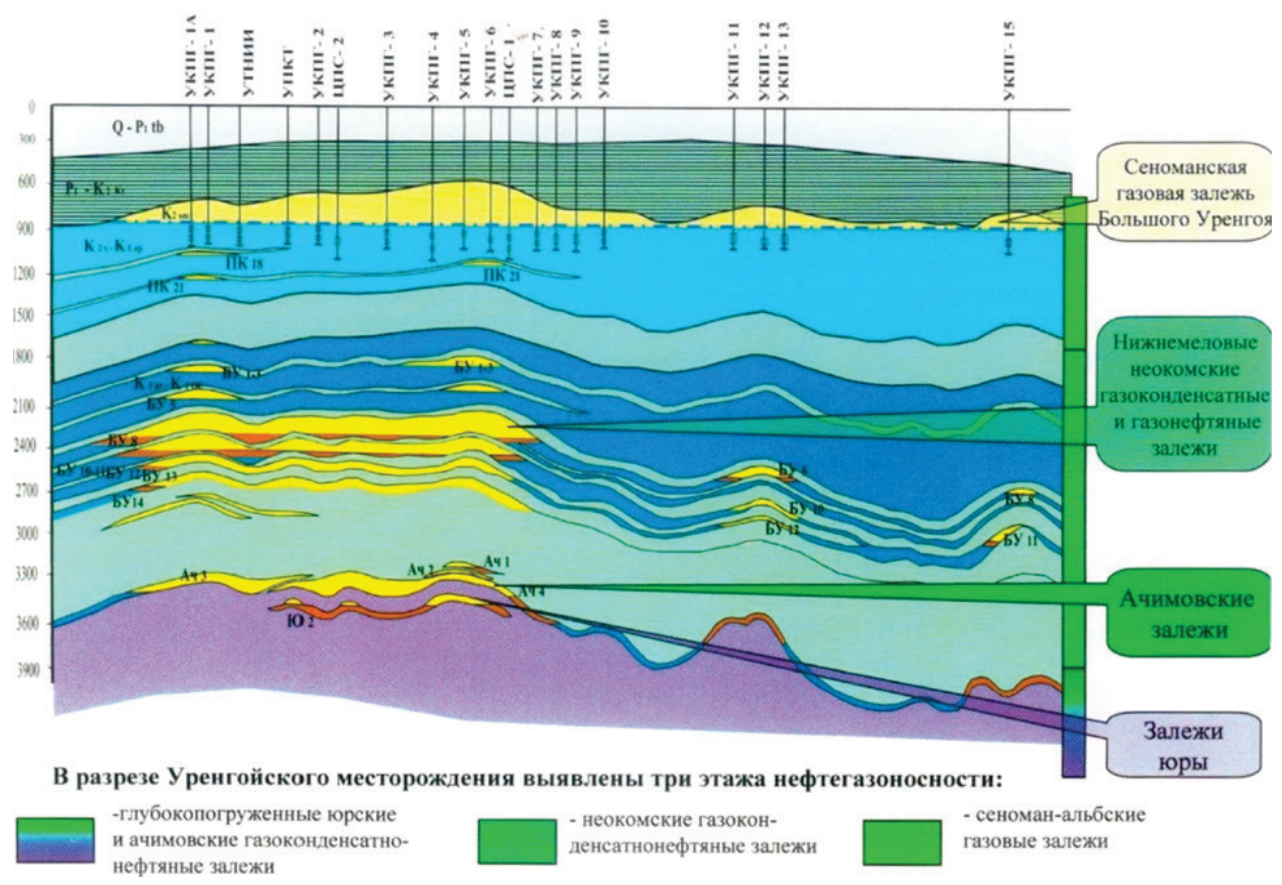

Рис. 2. Геологический разрез Уренгойского месторождения

Пластовые углеводородные системы ачимовских залежей Уренгойского нефтегазоконденсатного месторождения представлены шестью линзами $\mathrm{Aq}_{1}-\mathrm{Aq}_{6}$. Основные запасы сосредоточены в пластах $\mathrm{Aq}_{3-4}$ и $\mathrm{Aч}_{5}{ }^{2-3}$. Данные залежи характеризуются следующими параметрами: глубина залегания 3 500-4 100 м, проницаемость - 0,1-1,0 мД, пористость - $13 \%$, пластовое давление - 57,0-62,5 МПа, пластовая температура - 370-385 ${ }^{\circ} \mathrm{K}$ [20]. Жесткие термобарические условия залегания способствовали растворимости в газовой фазе тяжелых жидких компонентов. Потенциальное содержание конденсата классифицируется как высокое, и среднее значение составляет 360 г $\mathrm{m}^{3}$ на газ сепарации [21].

Предметом исследования являются параметры работы скважины, а именно - дебиты газа и газового конденсата, конденсатогазовый фактор (КГФ), потенциальное содержание конденсата в пластовом газе.

\section{Результаты}

Остановка эксплуатационной скважины по какой-либо причине и дальнейшее возобновление ее эксплуатации сказываются на потенциальном содержании конденсата в пластовом газе. Как итог, полученные значения потенциального содержания конденсата во время проведения комплексных исследований значительно возрастают по сравнению с истинными значениями, определенными на установках фазовых равновесий. При высоком содержании конденса-

№ 3, 2019 Нефть и газ 49 
та в пластовом газе аналогичное поведение скважины возможно, даже если она работала с незначительными депрессиями (менее $10 \%$ ).

Рассмотрим пример добывающей скв. 105 месторождения Карачаганак (рис. 3).

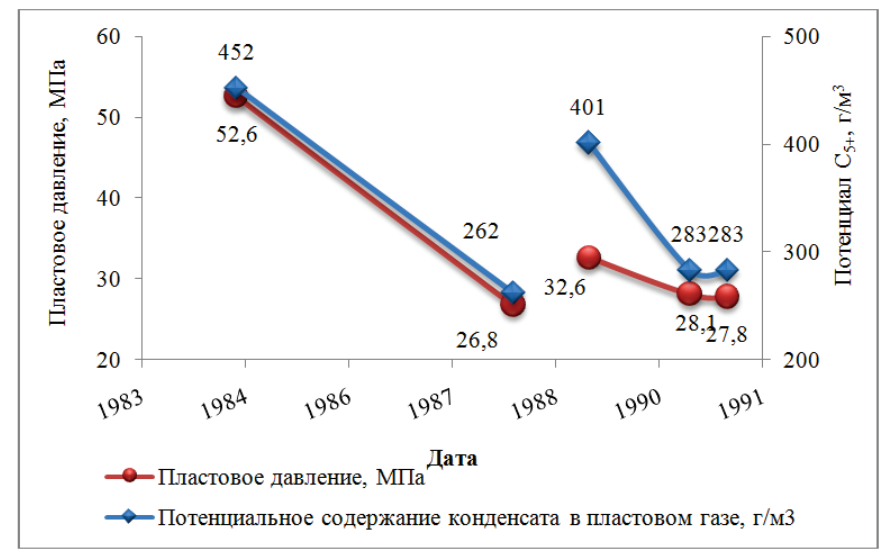

Рис. 3. Динамика пластового давления и потенциального содержания конденсата в пластовом газе

Начальное пластовое давление составляло 52,6 МПа, давление начала конденсации - 46,5 МПа, а потенциальное содержание конденсата - 425 г/м ${ }^{3}$. Скважина введена в эксплуатацию в октябре 1984 г., спустя 4 года, в августе 1988 г., осуществлены ее остановка и перевод в резервный фонд. Перед остановкой в июне 1988 г. при текущем пластовом давлении 26,8 МПа были проведены исследования скважины на газоконденсатность. В результате исследований установлено, что содержание конденсата снизилось до 262 г/м³. В июне 1989 г. при пластовом давлении 32,6 МПа скв. 105 была пущена на несколько дней для проведения газоконденсатных исследований. При исследованиях получены следующие результаты: содержание конденсата - 401 г/м ${ }^{3}$ пластового газа.

В ноябре 1989 г. скважина пущена в эксплуатацию. За год эксплуатации давление в скважине упало до 28,1 МПа, все характеристики конденсата сравнялись со значениями, которые были перед остановкой скважины. Через 5 месяцев (апрель 1991 г.) скважина вновь исследовалась, и была получены следующие параметры: пластовое давление - 27,8 МПа, потенциальное содержание конденсата - 283 г/ $\mathrm{M}^{3}$. Наиболее подробно с результатами можно ознакомиться в работе [22].

Далее рассмотрим пример остановки и его результаты на примере одной из скважин, ведущей добычу газоконденсатной смеси из пласта Ачч ${ }^{2-3}$ (рис. 4, 5). Скважина запущена в эксплуатацию в мае 1997 г., дебит газа сепарации не превышал 300 тыс. $\mathrm{m}^{3} /$ сут.

В августе 1998 г. был проведен ГРП - дебит газа сепарации возрос до 800 тыс. $\mathrm{m}^{3} /$ сут во второй месяц эксплуатации и резко снизился до 500 тыс. $\mathrm{m}^{3} /$ сут уже в следующем месяце. Это говорит о том, что даже ГРП не всегда приводит к увеличению продуктивности скважины и в данных условиях наблюдается дальнейшее снижение дебитов газа и конденсата более чем в 2 раза.

Повторный ГРП проведен в июне 2003 г., его результат очевиден, так как не произошло резкого снижения дебитов газа и конденсата. Зависимость снижения дебитов газа и конденсата описывается экспоненциальным уравнением 
и в дальнейшем используется для прогноза определения эффекта от отключения скважины. В ноябре 2006 г. скважина остановлена на 12 месяцев. После запуска скважины в эксплуатацию отмечается рост дебитов газа и конденсата.

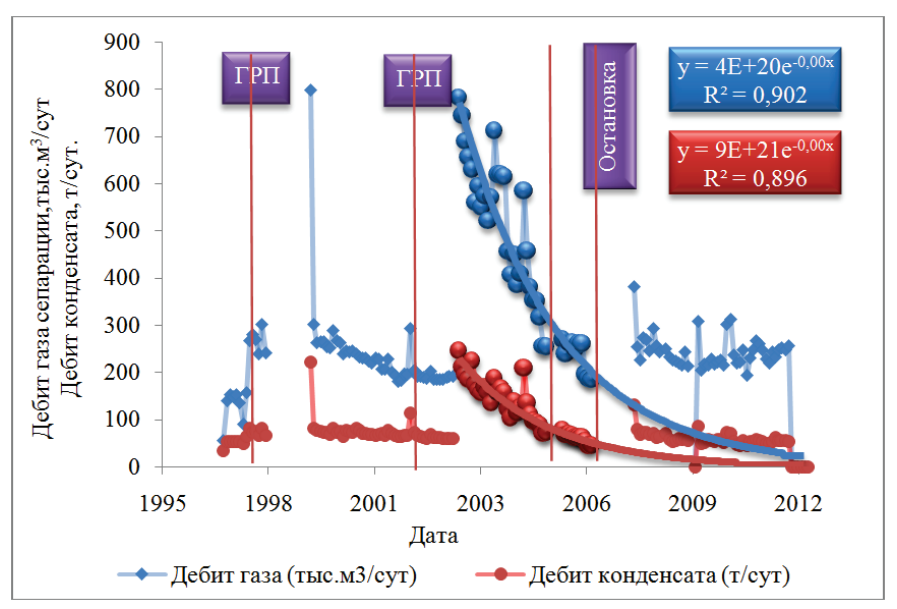

Рис. 4. Динамика дебитов газа и конденсата

\section{Обсуждение}

Переход газоконденсатной системы из однофазного в двухфазное состояние сопровождается зарождением новой - жидкой фазы во всем объеме углеводородной системы. Такие фазовые превращения характеризуются как равновесные. Переход из двухфазного состояния в однофазное (неравновесный процесс), ввиду различия составов паровой и жидкой фаз, сопровождается диффузией компонентов через межфазную границу. Ввиду малой площади межфазной границы, обусловленной поровым пространством, без дополнительного перемешивания углеводородной системы, процесс установления фазового равновесия занимает много времени. В результате имеет место гистерезис фазового перехода [23].

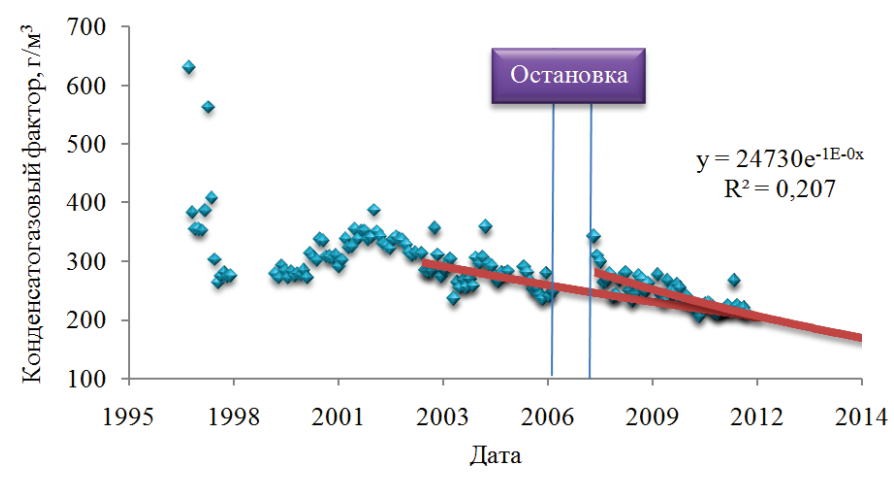

Рис. 5. Динамика изменения конденсатогазового фактора

Анализ динамики изменения конденсатогазового фактора по данной скважине был произведен следующим образом. База для прогноза - значение КГФ после повторного гидравлического разрыва пласта. Создание при ГРП высокопроводящих каналов привело к более быстрому изменению фазового 
состояния углеводородной системы, чем в поровом пространстве. КГФ на момент запуска скважины составлял $350 \mathrm{r}_{\mathrm{m}} \mathrm{M}^{3}$ и характеризовался последующей плавной регрессией. К моменту остановки скважины КГФ составил 250 г/м ${ }^{3}$. После длительной остановки скважины КГФ вернулся на прежний уровень 350 г/ $\mathrm{M}^{3}$, что свидетельствует об эффективности нестационарной работы скважины.

\section{Выводы}

- $\quad$ В низкопроницаемых коллекторах после проведения ГРП происходит снижение содержания конденсата в продукции скважин за счет интенсивного выпадения высококипящих фракций конденсата в околоскважинном пространстве.

- Предложен способ повышения содержания конденсата в продукции эксплуатационной скважины за счет ее нестационарной работы, предусматривающей остановку.

- $\quad$ В процессе остановки скважины происходят перераспределение, выравнивание давления в зоне дренирования и испарение выпавшего конденсата. При запуске скважины за счет проведенных мероприятий в ее продукции увеличивается содержание конденсата.

\section{Библиографический список}

1. Методы повышения продуктивности газоконденсатных скважин / А. И. Гриценко [и др.]. - М.: Недра, 1997. - 364 с.

2. Граф Т. Вертикальная и горизонтальная интеграция для преодоления крайне сложных проблем при эксплуатации низкопроницаемых газоконденсатных пластов Ачимовской свиты [Электронный ресурс] // 171169-RU SPE Conference Paper - 2014. - Available at: https://www.onepetro.org/conference-paper / SPE-171169.

3. Математическое и физическое моделирование теплового воздействия на газоконденсатные системы / В. М. Зайченко [и др.] // Вести газовой науки. - 2013. - № 1 (12). - С. 66-72.

4. Шандрыгин А. Н. Воздействие на газоконденсатные пласты закачкой рабочих агентов // Недропользование XXI век. - 2008. - № 3. - С. 74-77.

5. Шандрыгин А. Н. Методы повышения продуктивности газоконденсатных скважин, направленные на уменьшение или предотвращение накопления конденсата в призабойных зонах // Недропользование XXI век. - 2008. - № 6. - С. 67-71.

6. Корчажкина И. Ю. Математическое моделирование мероприятий по обработке призабойных зон газоконденсатных скважин различными агентами // Вести газовой науки. - 2010. - № 1. - С. 82-91.

7. Назаров А. В. Развитие математического моделирования для проектирования и анализа разработки нефтегазоконденсатных месторождений: дис. ... д-ра техн. наук. - Ухта, 2012. $-427 \mathrm{c}$.

8. Киреев С. В. Изучение механизма накопления конденсата в призабойной зоне пласта и методы повышения продуктивности газоконденсатных скважин: дис. ... канд. техн. наук. - М., 2000. - 143 с.

9. Умняев В. Г. Развитие методов акустического воздействия из скважин с целью повышения конденсатоотдачи пласта: Автореф. дис. ... канд. техн. наук. - Ухта, 2013. - 23 с.

10. Проблемы повышения производительности газоконденсатных скважин на поздней стадии разработки месторождений / М. Т. Абасов [и др.] // Геология нефти и газа. - 2003. № 3. - С. $48-52$.

11. Булейко В. М. Обоснование методов активного воздействия на углеводородные залежи плотных низкопроницаемых коллекторов на основе экспериментальных исследований поведения флюидов в пористых средах // Вести газовой науки. - 2011. - № 2 (7). - С. 110-123.

12. Моделирование и исследование влияния «конденсатной банки» на продуктивность газоконденсатных скважин с ГРП / А. Э. Игнатьев [и др.] // Нефтепромысловое дело. - 2011. - № 9. - C. 19-24. 
13. Технологии для заканчивания и многостадийного ГРП для сложных горизонтальных скважин с АВПД Ачимовских залежей Уренгойского месторождения [Электронный pecypc] / А. Абалев [и др.] // SPE Russian Oil and Gas Exploration \& Production Technical Conference and Exhibition (14-16 October, 2014). - Режим доступа: https://www.onepetro. org/conference-paper/SPE-171277-RU. DOI: 10.2118/171277-RU

14. Практический опыт увеличения продуктивности газоконденсатных скважин в низкопроницаемых коллекторах более чем на $30 \%$ благодаря комплексному подходу при строительстве и заканчивании скважин [Электронный ресурс] / М. Г. Жариков [и др.]. // SPE Russian Petroleum Technology Conference (26-28 October, 2015). - Режим доступа: https://www.onepetro.org/conference-paper/SPE-176535-RU. DOI: 10.2118/176535-RU

15. Размер ГРП имеет значение: опыт разработки мощных ачимовских отложений Уренгойского газоконденсатного месторождения / А. Юдин [и др.] // SPE Russian Petroleum Technology Conference (16-18 October, 2017). - Режим доступа: https://www.onepetro. org/conference-paper/SPE-187852-RU. DOI: 10.2118/187852-RU

16. A New Deliverability Testing Method for Gas Condensate Wells / Shi Juntai [et al.] // 131443-MS SPE Conference Paper - 2010. - Available at: https://www.onepetro.org/conferencepaper/SPE-1314432.

17. Обзор работ по теории фильтрации углеводородных систем / Б. А. Григорьев [и др.] // Вести газовой науки. - 2017. - № 2. - С. 182-202.

18. Гужов Н. А. Термогидродинамические основы добычи углеводородов при разработке газоконденсатных месторождений с воздействием на пласт: дис. ... д-ра техн. наук. M., 2000. $-474 \mathrm{c}$.

19. Шабаров А. Б., Заночуев С. А. Метод расчета изменения компонентного и фазового состава газоконденсатной смеси в призабойной зоне пласта // Вестник Тюменского государственного университета. Физико-математическое моделирование. Нефть, газ, энергетика. - 2015. - Т. 1, № 1. - С. 7-21.

20. Лапшин В. И., Волков А. Н., Константинов А. А. Газоконденсатные характеристики углеводородных флюидов нефтегазоконденсатных залежей (начальное определение и корректировки в процессе разработки) // Вести газовой науки. - 2014. - № 4. - С. 119-126.

21. Физико-химическая характеристика конденсатов ачимовских отложений Уренгойского нефтегазоконденсатного месторождения / А. Е. Рыжов [и др.] // Вести газовой науки. - 2013. - № 5 (16). - С. 91-98.

22. Исследование природных газоконденсатных систем / Н. В. Долгушин [и др.]. - Ухта, 1997. $-178 \mathrm{c}$.

23. Лобанова О. А. Моделирование неравновесного фазового поведения при разработке нефтяных и газоконденсатных залежей: дис. ... канд. техн. наук. - М., 2016. - 129 с.

\section{Сведения об авторах}

Инякин Владислав Витальевич, аспирант кафедры разработки и эксплуатации нефтяных и газовых месторождений, Тюменский индустриальный университет, 2.Tюмень, e-mail: injakinvv@tyuiu.ru

Мулявин Семен Федорович, д. т. н., профессор кафедры разработки и эксплуатации нефтяных и газовых месторождений, Тюменский индустриаль-ный университет, г. Тюмень

Усачев Игорь Анатольевич, заместитель начальника отдела испытания скважин департамента проектирования разработки месторождений нефти и газа, НАО "Сибирский научно-аналитический ијентр», 2. Тюмень

\section{Information about the authors}

Vladislav V. Inyakin, Postgraduate at the Department of Development and Exploitation of Oil and Gas Fields, Industrial University of Tyumen,e-mail: injakinvv@tyuiu.ru

Semen F. Mulyavin, Doctor of Engineering, Professor at the Department Development and Exploitation of Oil and Gas Fields, Industrial University of Tyumen

Igor A. Usachev, Assistant Head of Department Wellbore Testing, Design of an Oil and Gas Field Development, Siberian scientific-analytical centre NJSC, Tyumen 